\title{
Effect of Lewis number on ball-like lean limit flames
}

\author{
Zhen Zhou ${ }^{\mathrm{a}, *}$, Yuriy Shoshin ${ }^{\mathrm{a}}$, Francisco E. Hernández-Pérez ${ }^{\mathrm{b}}$, Jeroen A. van Oijen ${ }^{\mathrm{a}}$, Laurentius \\ P.H. de Goey ${ }^{\mathrm{a}}$ \\ ${ }^{a}$ Department of Mechanical Engineering, Eindhoven University of Technology, P.O. Box 513, 5600MB Eindhoven, \\ The Netherlands \\ ${ }^{b}$ Clean Combustion Research Center, King Abdullah University of Science and Technology, Thuwal 23955-6900, \\ Saudi Arabia
}

\begin{abstract}
The lean limit flames for three different fuel compositions premixed with air, representing three different mixture Lewis numbers, stabilized inside a tube in a downward flow are examined by experiments and numerical simulations. The $\mathrm{CH}^{*}$ chemiluminescence distribution in $\mathrm{CH}_{4}$-air and $\mathrm{CH}_{4}-\mathrm{H}_{2}$-air flames and the $\mathrm{OH}^{*}$ chemiluminescence distribution in $\mathrm{H}_{2}$-air flames are recorded in the experiments. Cell-like flames are observed for the $\mathrm{CH}_{4}$-air mixture for all tested equivalence ratios. However, for $\mathrm{CH}_{4}-\mathrm{H}_{2}$-air and $\mathrm{H}_{2}$-air flames, ball-like lean limit flames are observed. Flame temperature fields are measured using Rayleigh scattering. The experimentally observed lean limit flames are predicted qualitatively by numerical simulation with the mixture-averaged transport model and skeletal mechanism of $\mathrm{CH}_{4}$. The results of the simulations show that the entire lean limit flame of $\mathrm{CH}_{4}-\mathrm{H}_{2}$-air and $\mathrm{H}_{2}$-air mixtures are located inside a recirculation zone. However, for the lean limit $\mathrm{CH}_{4}$-air flame, only the leading edge is located inside the recirculation zone. A flame structure with negative flame displacement speed is observed for the leading edges of the predicted lean limit flames with all three different fuel compositions. As compared with 1D planar flames, the fuel transport caused by convection is less significant in the present 2D lean limit flames for the three different fuel compositions. For the trailing edges of the three predicted lean limit flames, a diffusion dominated flame structure is observed.

Keywords: Lewis Number, Lean Limit, Ball-like Flame, Cell-like Flame
\end{abstract}

\footnotetext{
*Corresponding author.

Email address: Z.Zhou1@tue.nl (Zhen Zhou)

Preprint submitted to Combustion and Flame
} 


\section{Introduction}

Ultra lean combustion has been considered as one of the most promising concepts for the utilization in advanced low emission and high efficiency combustion devices. Besides, hydrogen blending with hydrocarbon fuels is a potential approach for further extending the lean flammability limit and reducing emissions. However, it is a challenge to design combustors or burners which can operate near the lean limit using hydrogen-blended fuel. The combustion characteristics of hydrogen-blended fuel significantly differ from the traditional hydrocarbon fuels because addition of hydrogen reduces mixture Lewis number. Therefore, understanding of the Lewis number effect on lean limit combustion characteristics is crucial for the design of the combustors and burners operating near the lean limit conditions.

Extensive studies have been reported in the literature on the lean limit combustion characteristics. The experiments of Baker [1] in a standard flammability tube proposed by Coward and Jones [2] showed that the lean limit for upward propagating flames is lower than that for downward propagating flames due to gravity. Therefore, in order to avoid the buoyancy-induced natural convection, experimental studies on lean limit flames were conducted at micro-gravity condition. For examples, Maruta et al. [3] experimentally studied low speed counterflow premixed flames of near-limit methane-air mixtures at microgravity conditions in drop tower experiments. Qiao et al. $[4,5]$ measured the laminar flame speed of hydrogen and methane flames with different diluents near the lean limit using the propagating spherical flame method in drop tower experiments. Zhang et al. [6] investigated the effect of pressure on counterflow methane-air flames near the lean limit in drop tower experiments.

For low Lewis number flames, so-called flame balls [7] can exist near the lean limit at microgravity. Zeldovich [8] first theoretically predicted the possibility of existence of a spherical and purely diffusion controlled flame which can steadily burn in an unconfined medium of premixed reactants. However, he pointed out that adiabatic flame ball solutions are unstable, and hypothesized that flame balls may be stabilized by heat loss. Ronney [7] accidentally observed flame balls in ultra lean $\mathrm{H}_{2}$-air mixtures in a drop tower experiment. Subsequently, in parabolic flight experiments, Ronney et al. [9, 10] confirmed that flame balls can exist in other different near-limit 
low Lewis number mixtures. Furthermore, in space shuttle experiments, Ronney et al. [10] found that flame balls drifted away from each other. Buckmaster et al. [11] found that flame balls can be stabilized by radiative heat loss. Minaev et al. [12] further theoretically predicted that flame balls are self-drifting. Recently, Takase et al. [13] observed that a ball-like low Lewis number flame exists near the lean limit in a convective flow at micro-gravity. Fursenko et al. [14, 15] experimentally and numerically observed multiple ball-like lean limit flames in a low speed counterflow burner at micro-gravity conditions.

Although steady flame balls were considered non-existent at normal gravity condition, a transition from cell-like propagating flames to ball-like propagating flames in $\mathrm{H}_{2}-\mathrm{CH}_{4}$-air mixtures was observed by Shoshin and de Goey [16] in experiments on flame propagation in a tube under normal gravity condition. Shoshin et al. [17] further studied this ball-like lean limit flame by experiments and numerical simulations, and found that the temperature profile along the centerline for the balllike flame is very similar to that of the so-called travelling flame ball $[18,19,20]$. Subsequently, a ball-like lean limit flame was stabilized in a downward flow of premixed reactants [21]. A detailed comparison between experimental ball-like flames and numerical ball-like flames has been conducted by Hernández-Pérez et al. [22]. Despite the achievements of above studies, the effects of different fuel Lewis numbers on the lean limit flames in a tube remain unknown. Studies on lean limit flames in a tube for mixtures with different Lewis numbers can improve the understanding of the influences of Lewis number on the lean limit combustion properties and mechanisms which determine the lean flammability limit.

In this regard, the aims of the present study are as follows:

1. To experimentally study the influence of fuel Lewis number on the structure of a lean limit flame stabilized in a tube in a downward flow of premixed reactants.

2. To examine the fuel Lewis number effect on the lean limit flame structure by numerical simulations.

3. To investigate the differences between the lean limit flames stabilized inside a tube at normal gravity with 1D planar lean limit flames and 1D micro-gravity flame balls.

In the present study, pure $\mathrm{CH}_{4}$, pure $\mathrm{H}_{2}$, and a mixture of $40 \% \mathrm{H}_{2}$ and $60 \% \mathrm{CH}_{4}$ (specified on a 
molar basis) are selected as the fuels and air as oxidiser, to prepare lean mixtures with different Lewis numbers. In the following sections, the experimental setup and numerical approach are presented, and the experimental and numerical results are discussed. Finally, concluding remarks are given.

\section{Experimental Setup}

A schematic of the experimental setup is shown in Fig. 1. As described in the following section, line-wise Rayleigh scattering measurements have been performed along a line normal to the tube symmetry axis. In order to measure the temperature field of the whole flame, a burner is designed which allows traversing steadily the burning flame inside the tube through the measurement section. The burner consists of a hollow piston and a quartz tube with an inner diameter of $13.5 \mathrm{~mm}$ and a length of $100 \mathrm{~mm}$. A linear motor is connected to the piston, which moves the piston inside the tube with a constant speed. A perforated plate with thickness of $2 \mathrm{~mm}$ and holes of $0.4 \mathrm{~mm}$ diameter uniformly spaced with $0.3 \mathrm{~mm}$ pitch is mounted in the outlet of the piston to generate a uniform outlet flow profile. The slit between the piston and the tube is sealed by Teflon tape. Cylinder gases $\left(\mathrm{H}_{2}, \mathrm{CH}_{4}\right.$ and synthetic air- $\left.21 \% \mathrm{O}_{2}\right)$ with $99.9 \%$ purity are used in the experiments. The supply of $\mathrm{H}_{2}, \mathrm{CH}_{4}$ and synthetic air is controlled by the mass flow controllers with an uncertainty less than $1 \%$. The estimated uncertainty of experimental equivalence ratio caused by mass flow controllers is $2 \%$. Small fluctuations of mixtures composition (within $1 \%$ error), caused by inherent small flow instabilities introduced by mass flow controllers are damped by a buffer mounted in the gas line before the mixture is supplied to the burner. The mixture is ignited at the bottom of the burner using a household lighter at a sufficiently large equivalence ratio. After ignition, the equivalence ratio is slowly reduced and near-limit flames are stabilized at some distance from the perforated plate. The inlet mixture velocity is set close to the blow-off value for lean limit flames (determined in separate experiments). The temperature of the tube wall is kept nearly at room temperature by supplying cooling air to the outside of the quartz tube. The tube wall temperature is monitored by a pyrometer Pyrospot DT 40L.

Flame chemiluminescence is recorded at a fixed piston position with a distance of $30 \mathrm{~mm}$ from the outlet of the tube. An AVT-PIKE F-032b CCD-camera equipped with an interference filter 


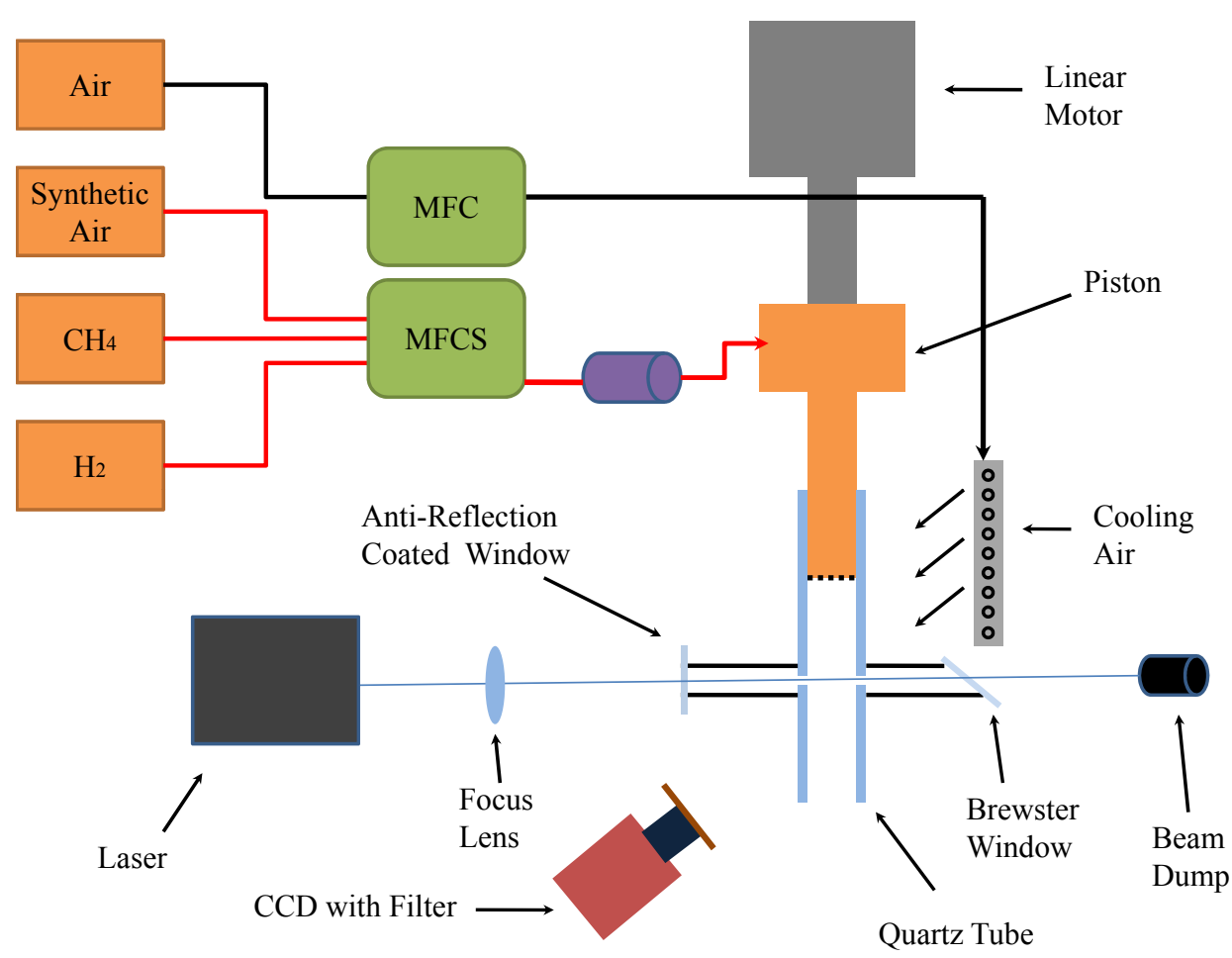

Figure 1: Schematic of experimental setup.

(430 nm and bandwidth $10 \mathrm{~nm}$ ) and an intensified CCD camera (Princeton Instruments ICCD) mounted with an interference filter (307 $\mathrm{nm}$ and bandwidth $10 \mathrm{~nm}$ ) are employed to record the $\mathrm{CH}^{*}$ and $\mathrm{OH}^{*}$ chemiluminescence for the $\mathrm{CH}_{4}$ contained flames and $\mathrm{H}_{2}$ flames, respectively. The chemiluminescence images show a line-of-sight integrated emission intensity. The in-plane radial emission intensity distributions are recovered by Abel inversion of the recorded image horizontal intensity profiles. The conditions of the experiments are listed in Table 1. Only fuel Lewis numbers less than unity are considered in the present study, because flame balls form only for below unit Lewis number mixtures. It can be seen in Table 1 that the effective fuel Lewis number decreases significantly from condition I to condition III. The details for the Rayleigh scattering temperature measurement are described in the next section. 
Table 1: Summary of conditions for the experiments with different equivalence ratios. * Mole fraction linearly weighted average based effective Lewis number for $\mathrm{CH}_{4}$ and $\mathrm{H}_{2}$ mixture.

\begin{tabular}{cccc}
\hline Condition & Fuel & Fuel Lewis Number $(\mathrm{Le})$ & $V_{\text {in }}(\mathrm{cm} / \mathrm{s})$ \\
\hline I & $\mathrm{CH}_{4}$ & 0.97 & 0.58 \\
II & $40 \% \mathrm{H}_{2}+60 \% \mathrm{CH}_{4}$ & $0.7^{*}$ & 0.72 \\
III & $\mathrm{H}_{2}$ & 0.296 & 0.73 \\
\hline
\end{tabular}

\section{Rayleigh Temperature Measurement}

A continuous blue laser with an output power of $1 \mathrm{~W}$ operated at $450 \mathrm{~nm}$ is used for the measurements. In order to avoid a strong background scattering light when the laser beam passes through the tube wall, two symmetrical holes with a diameter of $2 \mathrm{~mm}$ are drilled in the middle of the tube. Two metal tubes with an inner diameter of $6 \mathrm{~mm}$ are horizontally attached to the tube wall sharing the co-axis with both small holes. At the inlet side of the laser beam, the metal tube is fitted with a anti-reflection window, while a Brewster window is mounted to the outlet side of the laser beam. This combination allows to minimize forward scattering from the front window and reflection from the back window, minimizing thereby the background signal related to the stray light. To further reduce background radiation, the inner metal tube wall and half of the inner quartz tube wall are painted with black high temperature paint. The laser beam is focused in the center of the tube with a $15 \mathrm{~mm}$ focal length lens, procuring a nearly constant width beam of approximately $0.3 \mathrm{~mm}$ diameter inside the quartz tube. A flame inside the tube is scanned by moving the piston with a constant speed of $0.7 \mathrm{~mm} / \mathrm{s}$. The scattered light from the laser beam inside the tube is recorded by the AVT-PIKE F-032b CCD-camera with a frame rate of $8 \mathrm{fps}$. The camera lens is equipped with an interference filter (Center wavelength $450 \mathrm{~nm}$ and bandwidth $10 \mathrm{~nm}$ ) to filter out flame radiation. The Rayleigh scattering images recorded during the piston motion are utilized to reconstruct the temperature field inside the tube using the known image scale and frame rate. The measurements provide a resolution of $0.034 \mathrm{~mm}$ in horizontal direction and $0.175 \mathrm{~mm}$ in vertical direction.

For each location along the beam, the Rayleigh scattering signal is calculated by integrating the recorded intensities across the beam image (10 pixels). The background signal is estimated by 
averaging background signals integrated over 10 pixels at a distance of 20 pixels above and below the beam. A corrected Rayleigh scattering signal intensity is determined as,

$$
S_{c o r}=S_{r a w}-S_{b k g}
$$

where $S_{c o r}$ is the corrected signal, $S_{\text {raw }}$ is the initial recorded signal by camera and $S_{b k g}$ is the background signal.

The effective Rayleigh scattering cross section is calculated based on the mole fraction of species, which is expressed as

$$
\sigma_{e f f}=\sum x_{i} \sigma_{i}
$$

where $\sigma_{\text {eff }}$ is the effective Rayleigh scattering cross section, $x_{i}$ is the mole fraction of the $i^{\text {th }}$ species and $\sigma_{i}$ is the Rayleigh scattering cross section of the $i^{t h}$ species. A number of Rayleigh scattering cross sections for major species for different light wavelengths can be found in ref. [23]. The Rayleigh cross sections for major species at $450 \mathrm{~nm}$ are obtained by interpolation of the data presented in ref. [23]. The effective Rayleigh scattering cross section for the present lean limit flames is evaluated using numerically predicted distribution of species in the studied flames, as shown in Fig. 2. The effective Rayleigh scattering cross section for the studied lean limit flames is scaled by the effective Rayleigh cross section for the corresponding unburned mixture, as the calibration of the measurements are performed with the corresponding unburned mixture. Figure 2 shows that the influence of variations of the effective Rayleigh scattering cross section over the flame region on the precision of temperature measurements is small for lean limit flames. The estimated error related to the these variations does not exceed $2.5 \%$ and $1 \%$ for $\mathrm{CH}_{4}$-air flames and $\mathrm{H}_{2}$ containing flames, respectively.

For calculation of temperature, the flow is assumed to be a mixture of perfect gases obeying an ideal gas equation of state. The reference signal is recorded in the corresponding unburned mixture at room temperature $(300 \mathrm{~K})$. Finally, the temperature is calculated as

$$
T_{f}=T_{c a l} \frac{S_{c a l}}{S_{f}} \frac{\sigma_{f}}{\sigma_{c a l}}
$$




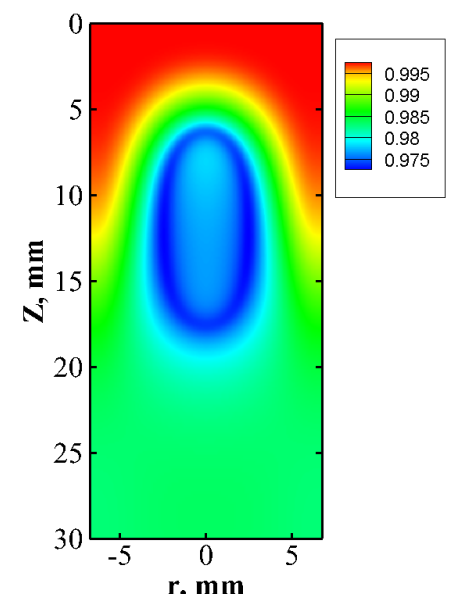

(a) $\phi=0.445$

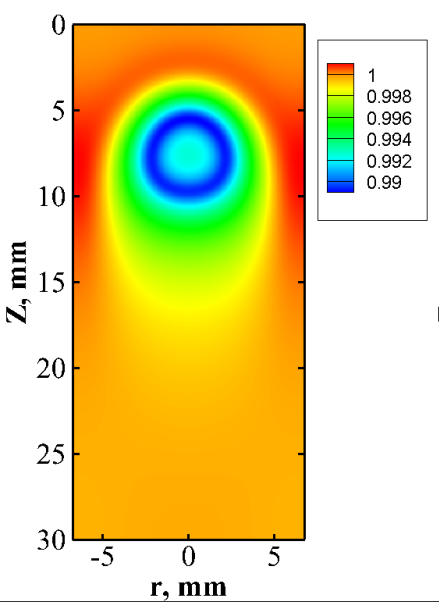

(b) $\phi=0.315$

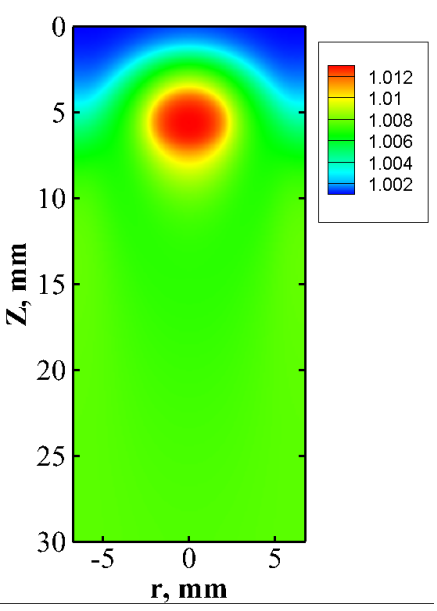

(c) $\phi=0.11$

Figure 2: Scaled effective Rayleigh scattering cross section for different lean limit flames. a. $\mathrm{CH}_{4}$-air; b. $\mathrm{H}_{2}$ - $\mathrm{CH}_{4}$-air; c. $\mathrm{H}_{2}$-air. The effective Rayleigh scattering cross section for lean limit flames is scaled by the effective Rayleigh scattering cross section of the corresponding unburned mixture.

where $T_{f}$ is the measured temperature, $T_{c a l}$ is the reference temperature, $S_{c a l}$ is the backgroundcorrected Rayleigh scattering signal intensity for calibration, $S_{f}$ is the background-corrected Rayleigh scattering signal intensity for the flames and $\sigma_{c a l}$ and $\sigma_{f}$ are the effective Rayleigh cross section for calibration (unburned mixture) and flames, respectively. For the $\sigma_{f}$, the averaged effective cross-section between its minimum and the maximum values in simulated flames is taken.

\section{Numerical Approach}

The numerical approach is similar to the one used in previous work [22] and here only a brief description of it is given. The flames under consideration are mathematically described by the conservation equations of mass, momentum, energy and species in a cylindrical coordinate system, as described in [22]. The flow is treated as a mixture of perfect gases under the assumption of an ideal gas equation of state. The set of governing equations is solved by the body-fitted, multiblock, adaptive mesh refinement, finite-volume framework that has been originally developed by Groth and co-researchers [22, 24, 25]. Thermodynamic properties, transport properties and species net production/destruction rate are all computed by the open-source library CANTERA [26].

In the simulations, the computational domain is a cylindrical channel with a radius of $6.75 \mathrm{~mm}$ and a height of $30 \mathrm{~mm}$, as shown in Fig. 3. The flames under study are laminar and axisymmetric. 
Hence the flames are simulated in two dimensions. The left boundary of the domain aligns the axis of symmetry. The upper boundary is assumed to be isothermal with a temperature of 300 $\mathrm{K}$ which accounts for the diffusion of fuel/air mixture across the upper boundary. The fuel/air mixture is supplied uniformly from the upper boundary. The right boundary is treated as a nonslip and iso-thermal boundary with a temperature of $300 \mathrm{~K}$ according to the temperature of the tube wall in the experiments. The lower boundary is modelled as a free outflow. The diffusion velocity is computed using the mixture-averaged transport model [22]. The skeletal mechanism of Smooke for $\mathrm{CH}_{4}$ [27] is employed which consists of 16 species and 25 reversible elementary reactions. This skeletal mechanism obtained good qualitative results in the simulation of ball-like lean limit flames in our previous research [17]. Gravity and radiative heat loss are taken into consideration. Thermal radiation is modelled via the optically-thin Planck model. The Planck mean absorption coefficient of the mixture is evaluated from the major radiating species $\mathrm{CO}_{2}$, $\mathrm{H}_{2} \mathrm{O}$ and $\mathrm{CO}$. The individual coefficients are calculated using a statistical narrow-band model and the dataset of Soufiani and Taine [28]. The solutions are obtained with up to three levels of mesh refinement, achieving a minimum grid space of $44 \mu \mathrm{m}$ for all the cases. These levels of resolution are found to be sufficient to get grid-independent solutions due to the rapid increase of flame thickness for near lean limit flames. More details of the numerical method can be found in [22]. A summary of the conditions for the simulated cases is given in Table 2. The 1D planar flames and 1D micro-gravity flame balls are computed using the in-house code CHEM1D [29], employing different transport and chemistry models.

\section{Results and Discussion}

\subsection{Flame shape}

Figure 4 shows the experimental Abel inverted $\mathrm{CH}^{*}$ chemiluminescence distributions for $\mathrm{CH}_{4}$ air and $\mathrm{CH}_{4}-\mathrm{H}_{2}$-air flames and the $\mathrm{OH}^{*}$ chemiluminescence distributions for $\mathrm{H}_{2}$-air flames as a function of equivalence ratio. It is seen that, for $\mathrm{CH}_{4}$-air flames, cell-like flames are formed at all tested equivalence ratios. With the decrease of equivalence ratio, the flame becomes smaller and the trailing edge of the flame becomes brighter. The leanest $2 \mathrm{D} \mathrm{CH}_{4}$-air flame is obtained at 


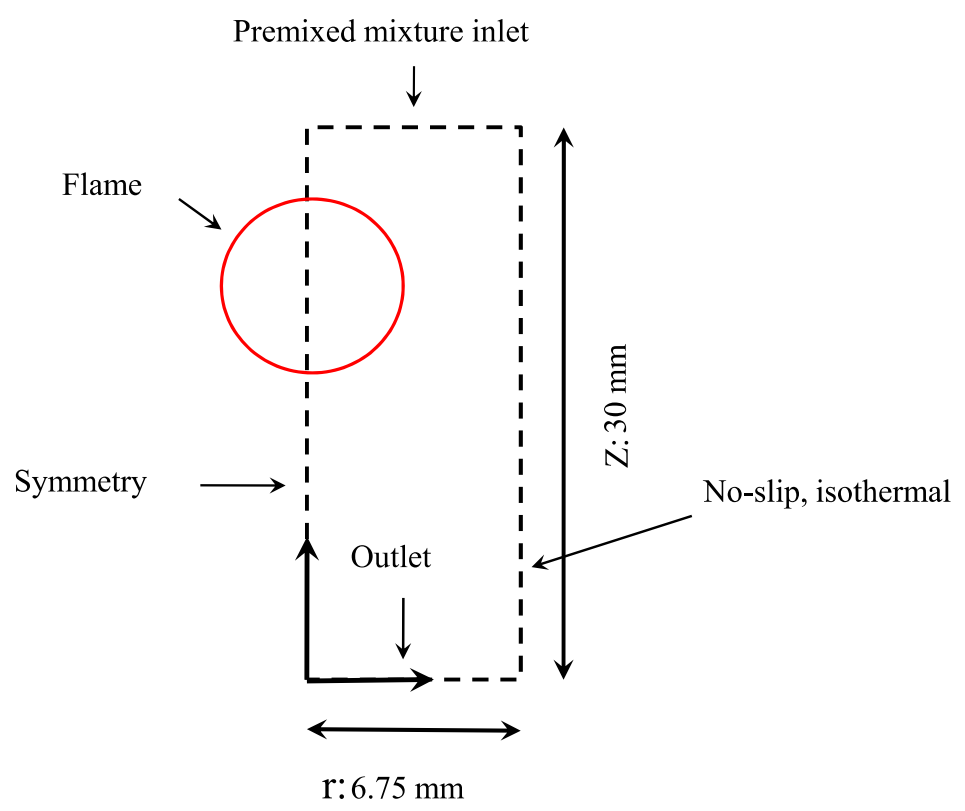

Figure 3: Schematic of the computational domain and boundary conditions.

Table 2: Summary of conditions for the simulated cases with the tube diameter of $13.5 \mathrm{~mm}$.

\begin{tabular}{cccc}
\hline Case & Fuel & $V_{\text {in }}(\mathrm{cm} / \mathrm{s})$ & $\phi$ \\
\hline $\mathrm{A}$ & $\mathrm{CH}_{4}$ & 0.58 & 0.49 \\
$\mathrm{~B}$ & $\mathrm{CH}_{4}$ & 0.58 & 0.47 \\
$\mathrm{C}$ & $\mathrm{CH}_{4}$ & 0.58 & 0.45 \\
$\mathrm{D}$ & $\mathrm{CH}_{4}$ & 0.58 & 0.445 \\
$\mathrm{E}$ & $40 \% \mathrm{H}_{2}+60 \% \mathrm{CH}_{4}$ & 0.72 & 0.40 \\
$\mathrm{~F}$ & $40 \% \mathrm{H}_{2}+60 \% \mathrm{CH}_{4}$ & 0.72 & 0.35 \\
$\mathrm{G}$ & $40 \% \mathrm{H}_{2}+60 \% \mathrm{CH}_{4}$ & 0.72 & 0.33 \\
$\mathrm{H}$ & $40 \% \mathrm{H}_{2}+60 \% \mathrm{CH}_{4}$ & 0.72 & 0.315 \\
$\mathrm{I}$ & $\mathrm{H}_{2}$ & 0.73 & 0.17 \\
$\mathrm{~J}$ & $\mathrm{H}_{2}$ & 0.73 & 0.15 \\
$\mathrm{~K}$ & $\mathrm{H}_{2}$ & 0.73 & 0.13 \\
$\mathrm{~L}$ & $\mathrm{H}_{2}$ & 0.73 & 0.11 \\
\hline
\end{tabular}

$\phi=0.48$. This value is only slightly lower than the lean limit for 1D planar flame obtained with simulations, as show in Table 3, which can be explained by the weakness of preferential diffusion in $2 \mathrm{D} \mathrm{CH}_{4}$-air flames for which the effective Lewis number is close to unity. Figure 4 further shows that a transition from cell-like flame to a nearly spherical ball-like flame ${ }^{1}$ is observed with

\footnotetext{
${ }^{1}$ We call these flames "ball-like flames" based on their appearance. This terminology is commonly used for enclosed nearly-spherical or ellipsoidal flamelets in low Lewis number lean-limit mixtures [13, 14, 19, 30].
} 
decreasing equivalence ratio in $\mathrm{CH}_{4}-\mathrm{H}_{2}$-air and $\mathrm{H}_{2}$-air mixtures. The lean limit ball-like flame for $\mathrm{H}_{2}$-air is smaller than that for $\mathrm{CH}_{4}-\mathrm{H}_{2}$-air. Additionally, the equivalence ratio of the lean limit 2D CH $\mathrm{CH}_{4}-\mathrm{H}_{2}$-air and $\mathrm{H}_{2}$-air flames are significantly lower than that of the corresponding 1D planar flames (see Table 3). This is because preferential diffusion effects greatly increase the local equivalence ratio in these small Lewis number 2D flames with respect to the inlet equivalence ratio. Changes of local equivalence ratio for the three different fuel mixture flames will be discussed further below, based on numerical predictions. At the same time, the simulated lean limit of 1D micro-gravity $\mathrm{CH}_{4}-\mathrm{H}_{2}$-air and $\mathrm{H}_{2}$-air flame balls are slightly lower than that of experimental $2 \mathrm{D}$ flames (see Table 3). The difference in flammability limits for the studied ball-like flames and micro-gravity flame balls can be attributed to the heat losses related to convection and conduction to the tube wall for the studied 2D flames.

The above experimentally observed phenomena are numerically predicted with the mixtureaveraged transport model and the skeletal chemical mechanism for $\mathrm{CH}_{4}$ [27]. Figure 5 displays the distributions of chemical heat release rates and streamlines for different fuel compositions at different equivalence ratios. It shows that the numerical simulations can qualitatively predict the change of flame shapes with decreasing equivalence ratio for all three different fuel compositions. The predicted lean limit for the $2 \mathrm{D} \mathrm{CH}_{4}$-air flame is lower than the experimental lean limit while that of $\mathrm{CH}_{4}-\mathrm{H}_{2}$-air and $\mathrm{H}_{2}$-air flames are slightly higher than the experimental lean limit (Table 3). The discrepancy can be attributed to the uncertainties of the chemical mechanism and transport model. Figure 5 also shows that a recirculation zone occurs as the lean limit is approached for all three fuel compositions, which is due to the increase of the buoyancy induced convection relative to flame burning velocity. The lean limit flames for $\mathrm{CH}_{4}-\mathrm{H}_{2}$-air and $\mathrm{H}_{2}$-air mixtures are located entirely inside the recirculation zone. However, for the lean limit flame of the $\mathrm{CH}_{4}$-air mixture, only the leading edge is located inside the recirculation zone. 

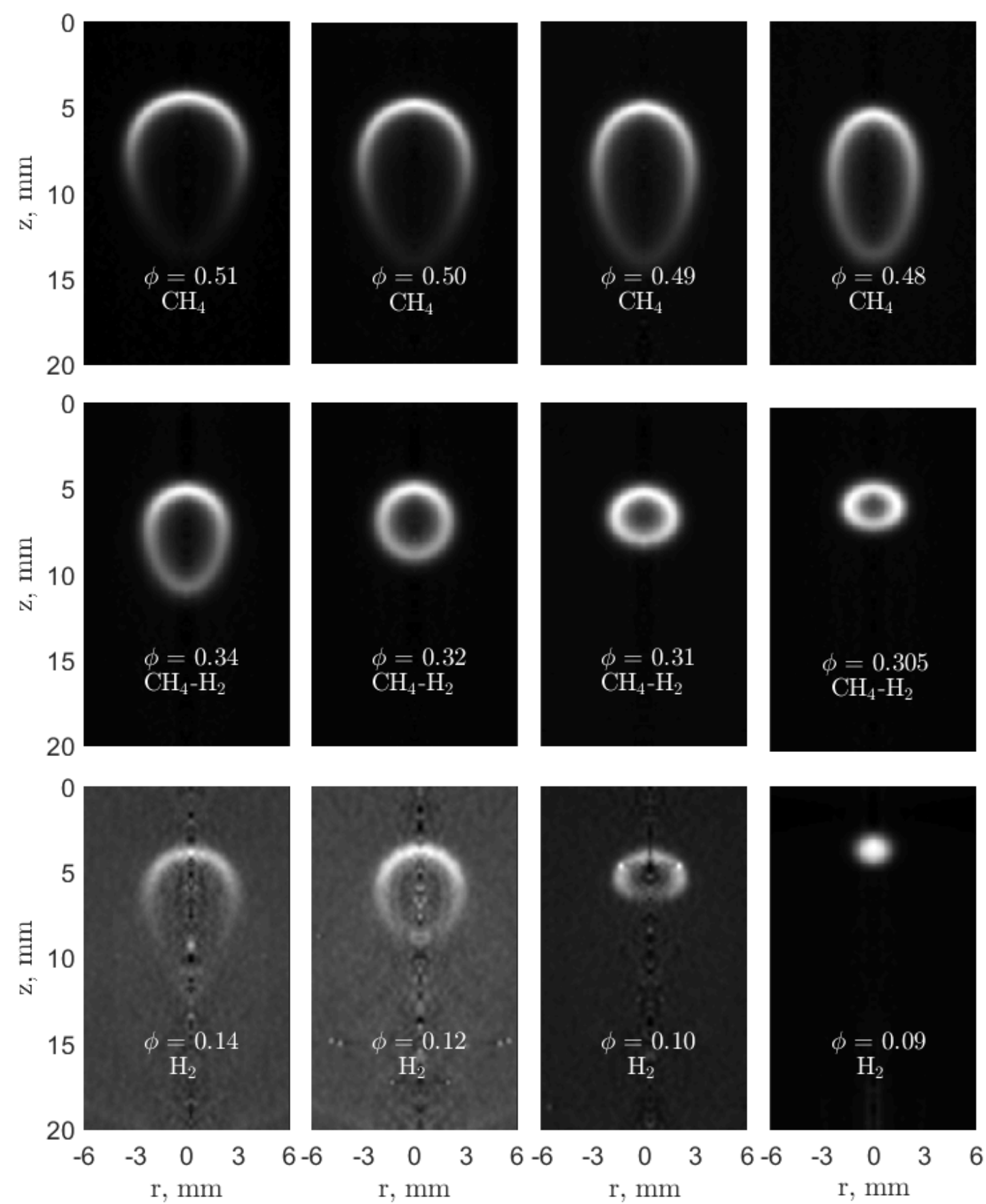

Figure 4: The $\mathrm{CH}^{*}$ chemiluminescence distributions for $\mathrm{CH}_{4}$-air and $40 \% \mathrm{H}_{2}-60 \% \mathrm{CH}_{4}$-air flames and $\mathrm{OH}^{*}$ chemiluminescence distributions for $\mathrm{H}_{2}$-air flames with different equivalence ratios. Natural chemiluminescence is recorded for the lean limit ball-like flame of $\mathrm{H}_{2}$-air mixture. 


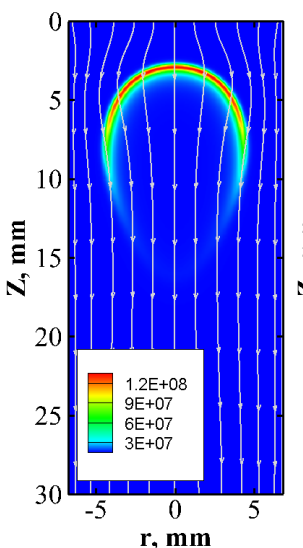

(a) $\phi=0.49$

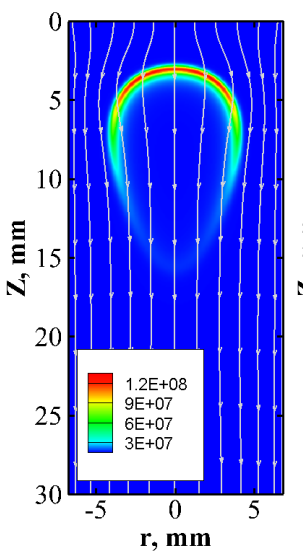

(e) $\phi=0.40$

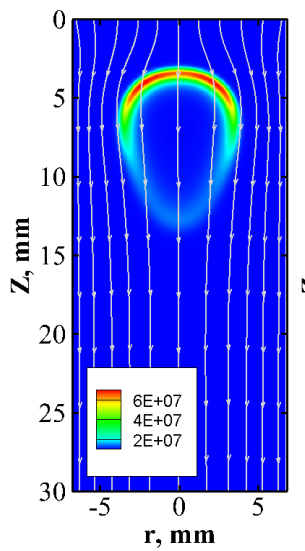

(i) $\phi=0.17$

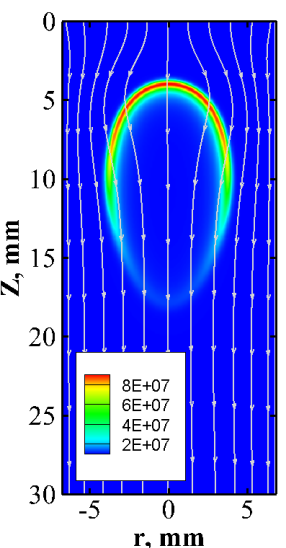

(b) $\phi=0.47$

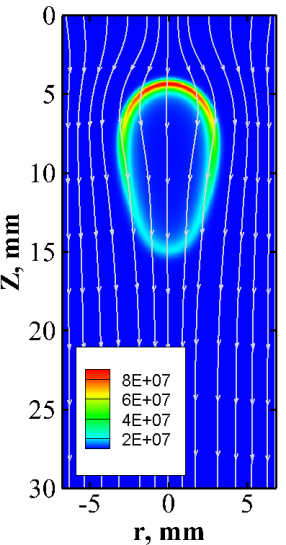

(f) $\phi=0.35$

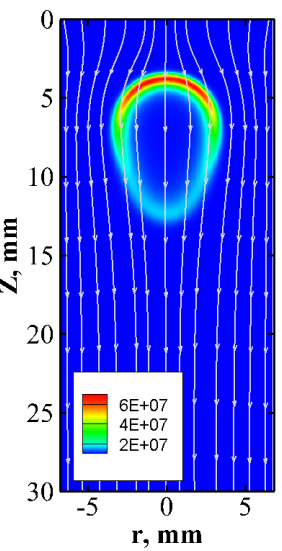

(j) $\phi=0.15$

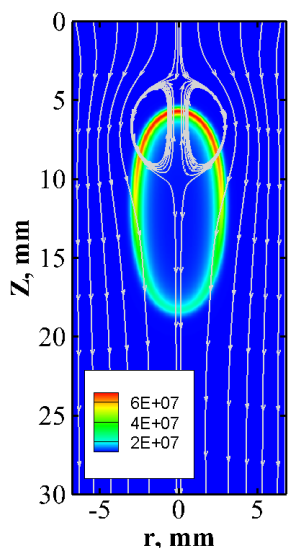

(c) $\phi=0.45$

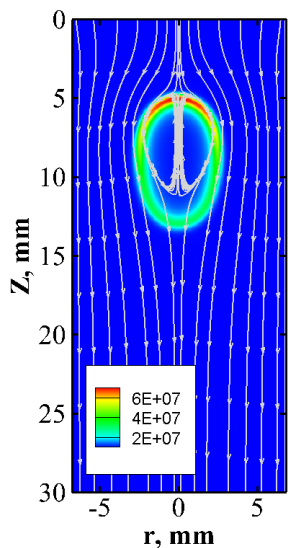

(g) $\phi=0.33$

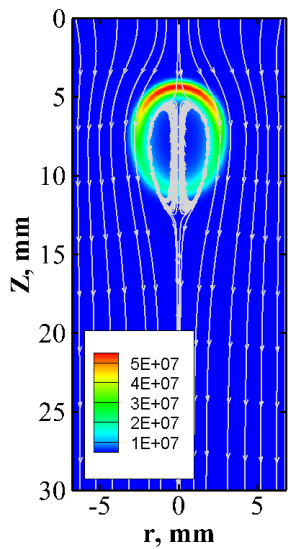

(k) $\phi=0.13$

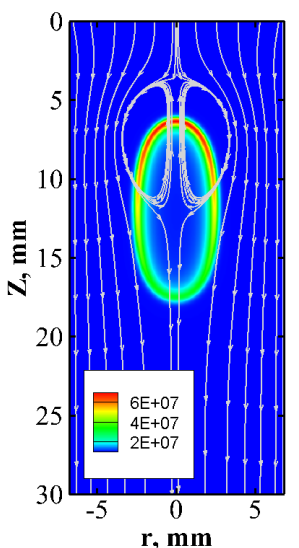

(d) $\phi=0.445$

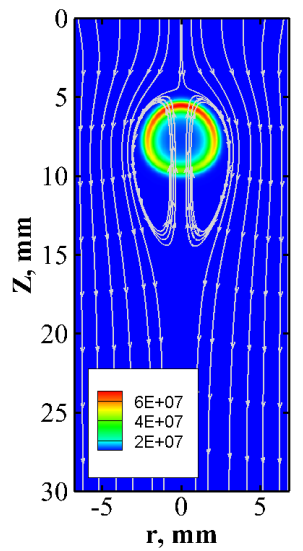

(h) $\phi=0.315$

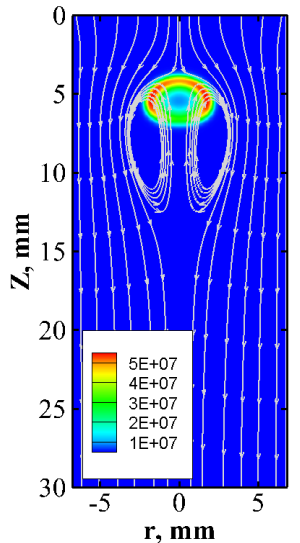

(1) $\phi=0.11$

Figure 5: Distribution of chemical heat release $\left(\mathrm{W} / \mathrm{m}^{3}\right)$ and flow streamlines for the flames studied in the simulations with mixture-averaged transport model and skeletal mechanism at different fuel compositions. (a-d): $\mathrm{CH}_{4}$; (e-h): $\mathrm{CH}_{4}-\mathrm{H}_{2} ;(\mathrm{i}-\mathrm{l}): \mathrm{H}_{2}$. 
Table 3: Summary of the equivalence ratio at the lean flammability limit for different types of flames with different fuel compositions. The lean limit of 1D planar flames and 1D micro-gravity flame balls are computed with multicomponent transport model with Soret diffusion, GRI 3.0 mechanism and optically thin radiation model.

\begin{tabular}{cccccc}
\hline Fuel & Le & Exp. 2D flame & Num. 2D flame & 1D flat flame & 1D flame ball \\
\hline $\mathrm{CH}_{4}$ & 0.97 & 0.480 & 0.445 & 0.497 & \\
$40 \% \mathrm{H}_{2}+60 \% \mathrm{CH}_{4}$ & 0.7 & 0.305 & 0.315 & 0.446 & 0.270 \\
$\mathrm{H}_{2}$ & 0.296 & 0.090 & 0.110 & 0.295 & 0.073 \\
\hline
\end{tabular}




\subsection{Flame temperature}

Figure 6 shows the numerically and experimentally measured lean limit flame temperature fields with different fuel compositions and the distributions of flame temperature along the flame centerline. Since the signal to noise ratio for Rayleigh scattering measurements decreases in the right part of the test section for cases $(\mathrm{d}, \mathrm{e})$, only the left part of the flame temperature field is used. A very good agreement is observed between numerical simulations and experimental measurements for the peak temperatures along the flame centerline. However, the discrepancies between simulated and experimental flame sizes and stand-off distances are substantial. This can be explained by the imperfection of the numerical models. The predictions for lean limit flames are very sensitive to the choice of chemistry and transport models [22]. It is further seen in Fig. 6 that, with decreasing Lewis number, the lean limit flame burns at a lower temperature.

Maximum flame temperatures for the 2D numerical and experimental flames with different fuel compositions are compared with that for 1D planar flames and 1D micro-gravity flame balls as a function of equivalence ratio. The results are presented in Fig. 7. The maximum flame temperature for the 2D numerical and experimental flames is taken from the maximum temperature along the centerline. It shows that, for $\mathrm{CH}_{4}$-air flames, 1D planar flame temperature and 2D predicted and measured flame temperatures decrease with the decrease of equivalence ratio. Although the predicted lean limits for 1D and 2D flames and the experimentally obtained lean limit for 2D flames are different, the maximum flame temperatures of these flames converge to nearly the same value as the equivalence ratio approaches the lean limit. For $\mathrm{CH}_{4}-\mathrm{H}_{2}$-air flames, both 1D planar flame temperature and 2D flame temperature decrease with the decrease of equivalence ratio. However, the 1D flame ball temperature increases with the decrease of equivalence ratio. The flame temperatures for these three types of flame also converge to nearly the same value with decreasing equivalence ratio. For $\mathrm{H}_{2}$-air flames, the trend for the change of temperature with the decrease of equivalence ratio for three types of flame is similar to that of $\mathrm{CH}_{4}-\mathrm{H}_{2}$-air flames.

\subsection{Flame structure}

Figure 8 displays the numerical distributions of the normalized chemical heat release, the normalized temperature and the scaled mass fraction of species along the centerline for different 


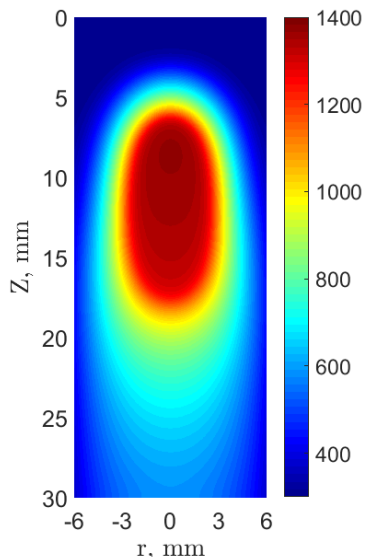

(a) $\phi=0.445$

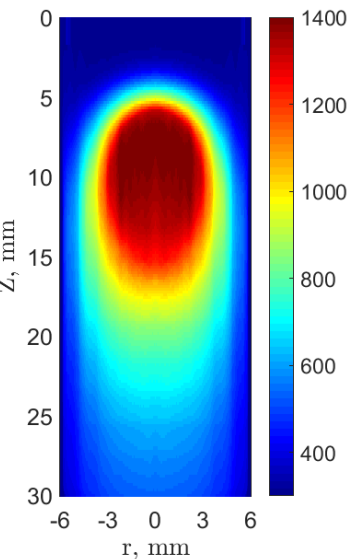

(d) $\phi=0.48$

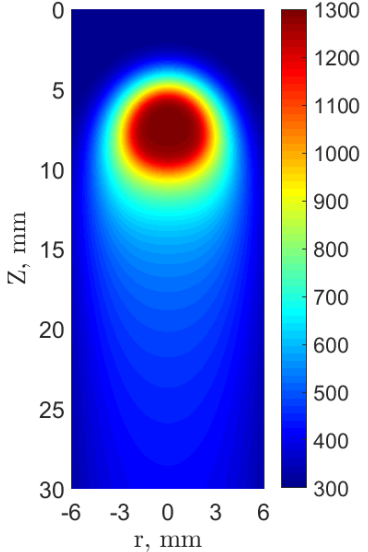

(b) $\phi=0.315$

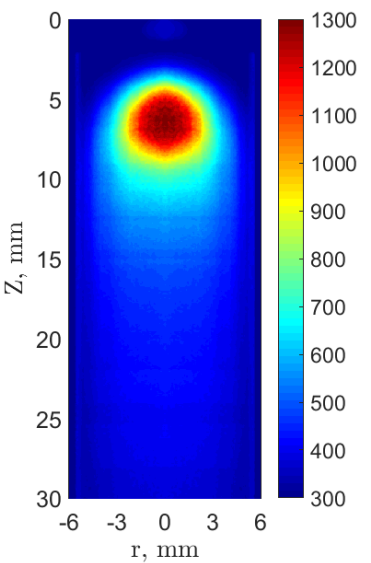

(e) $\phi=0.305$

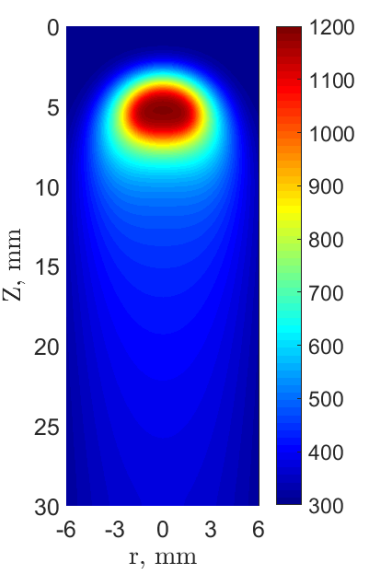

(c) $\phi=0.11$

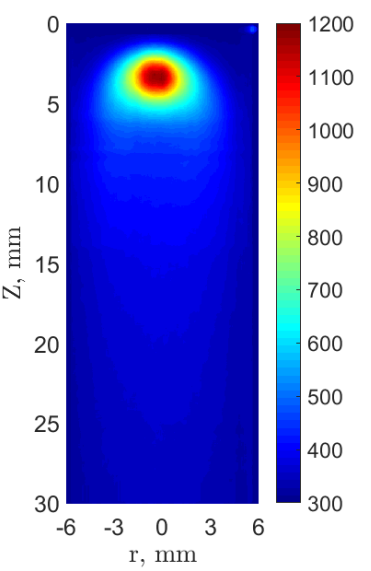

(f) $\phi=0.09$

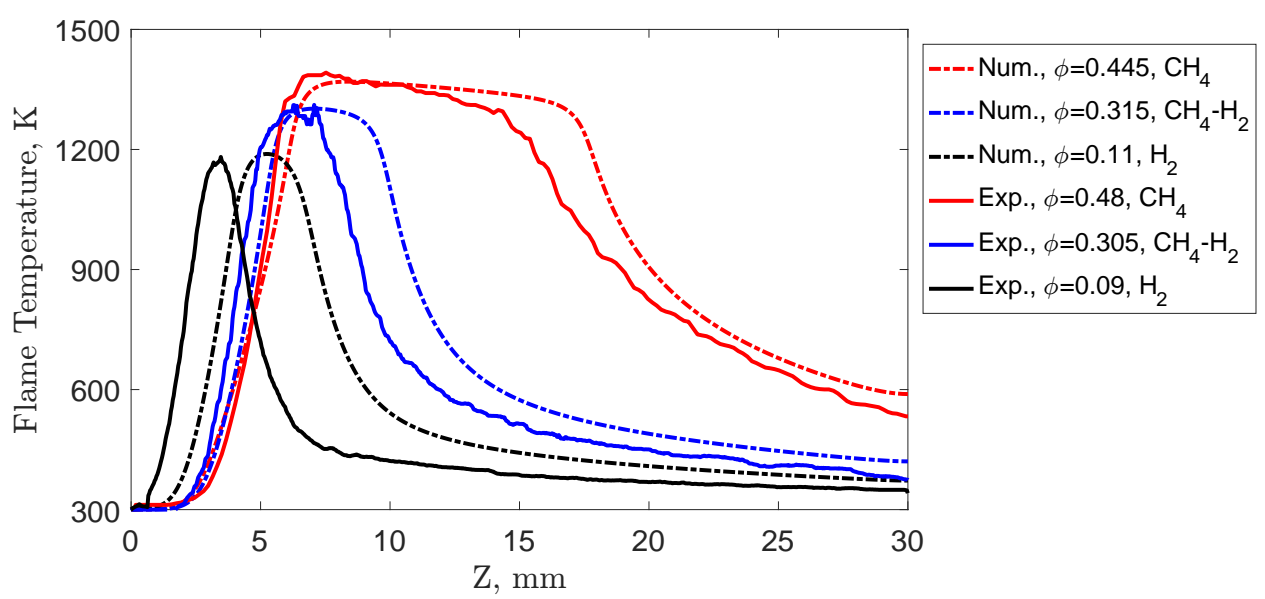

(g)

Figure 6: Numerical (a-c) and experimental (d-f) lean limit flame temperature field. (g): Distributions of numerical and experimental lean limit flame temperature along centerline. (a,d): $\mathrm{CH}_{4}$-air; (b,e): $\mathrm{CH}_{4}-\mathrm{H}_{2}$-air; $(\mathrm{c}, \mathrm{f}): \mathrm{H}_{2}$-air. The unit of temperature for above figures is Kelvin $(\mathrm{K})$. 

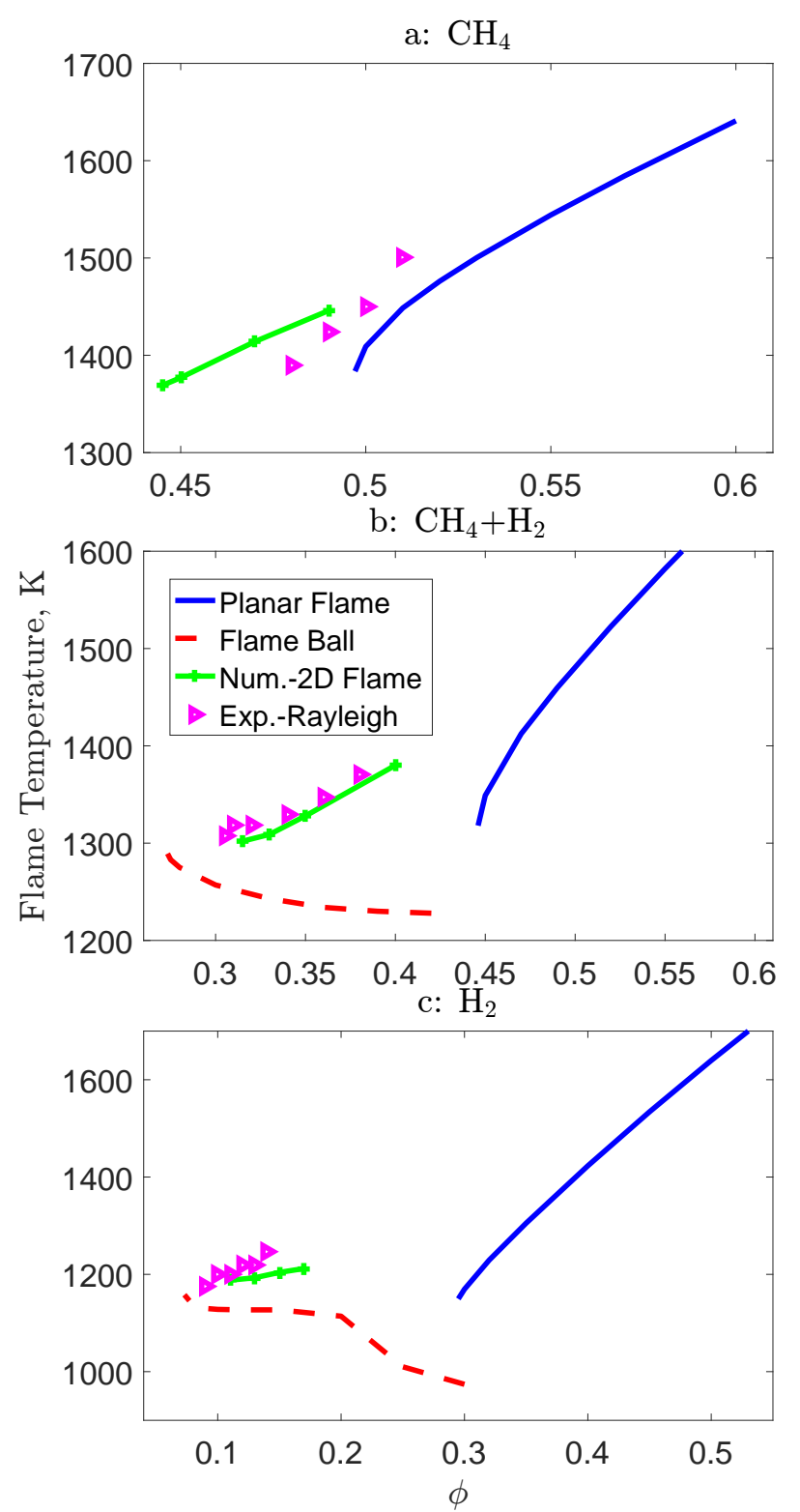

Figure 7: Flame temperature of 1D planar flame, 1D micro-gravity flame ball and 2D numerical and experimental flame as function of equivalence ratio. a. $\mathrm{CH}_{4}$-air, b. $\mathrm{CH}_{4}-\mathrm{H}_{2}$-air, c. $\mathrm{H}_{2}$-air.

equivalence ratios with different fuel compositions. The chemical heat release is normalized by its maximum value in the domain. The normalized temperature is defined as, $c=\left(T-T_{u}\right) /\left(T_{b}-T_{u}\right)$, where $T_{u}$ and $T_{b}$ are the unburned mixture temperature and maximum flame temperature. The mole fraction of species is scaled by the maximum mole fraction of $\mathrm{H}_{2} \mathrm{O}$. It is seen that the mole fraction of fuels first decreases and then increases from the inlet side to the outlet side for all sim- 
ulated cases. It is also seen that the increase in fuel mole fraction of the trailing edges is enhanced with decreasing equivalence ratio, especially for low Lewis number flames. This leads to the enhancement in the heat release of the trailing edge with the decrease of equivalence ratio and more so for lower Lewis number flames: a more uniform, closed flame front forms for low Lewis number flames near the lean limit. This is because flames are smaller in leaner mixtures and consume less fuel, allowing for a larger amount of fuel to leak between the flame and the tube wall and then feed the bottom part of the flame by diffusion. This effect is more prominent for smaller Lewis number flames, for which lean limit flames are smaller.

While 1D micro-gravity flame balls are purely diffusional flames, in 2D ball-like flames both diffusion and convection transport species and thermal energy. Qualitatively, the relative role of diffusional and convective transport in the studied 2D flames can be studied by comparison of the corresponding fluxes of fuel gases plotted as a function of normalized temperature, $c$, in the flame region with similar plots for 1D micro-gravity flame balls and 1D planar flames. The convective and diffusive fluxes of fuels are determined as follows:

$$
\begin{gathered}
F_{\text {con }, i}=\rho_{i} V \\
F_{d i f, i}=-\rho D_{i m} \nabla Y_{i}
\end{gathered}
$$

where, $F_{c o n, i}$ is the convective flux of species $i, F_{d i f, i}$ is the diffusive flux of species $i, \rho_{i}$ is the density of species $i, \rho$ is the mixture density, $V$ is the local velocity, $D_{i m}$ is the mixture-averaged diffusion coefficients of species $i$, and $Y_{i}$ is the mass fraction of species $i$. Figure 9 shows such plots, based on numerical results, for 1D flame balls and planar flames for three fuel compositions near the lean limit ((a) $\mathrm{CH}_{4}: \phi=0.5$ (planar flame); (b) $\mathrm{CH}_{4}-\mathrm{H}_{2}: \phi=0.46$ (planar flame) and $\phi=$ 0.275 (flame ball); (c) $\mathrm{H}_{2}: \phi=0.30$ (planar flame) and $\phi=0.08$ (flame ball)). Two steady solutions can be obtained for 1D flame balls, a large one and a small one. The two branches converge to one solution as the lean flammability limit is approached. Therefore, the lean limit 1D flame ball solutions are provided for the comparison with the ball-like lean limit flames. It is seen in Fig. 9 that the convective flux of $\mathrm{CH}_{4}$ in $1 \mathrm{D}$ planar flames decreases almost linearly in the preheat zone 


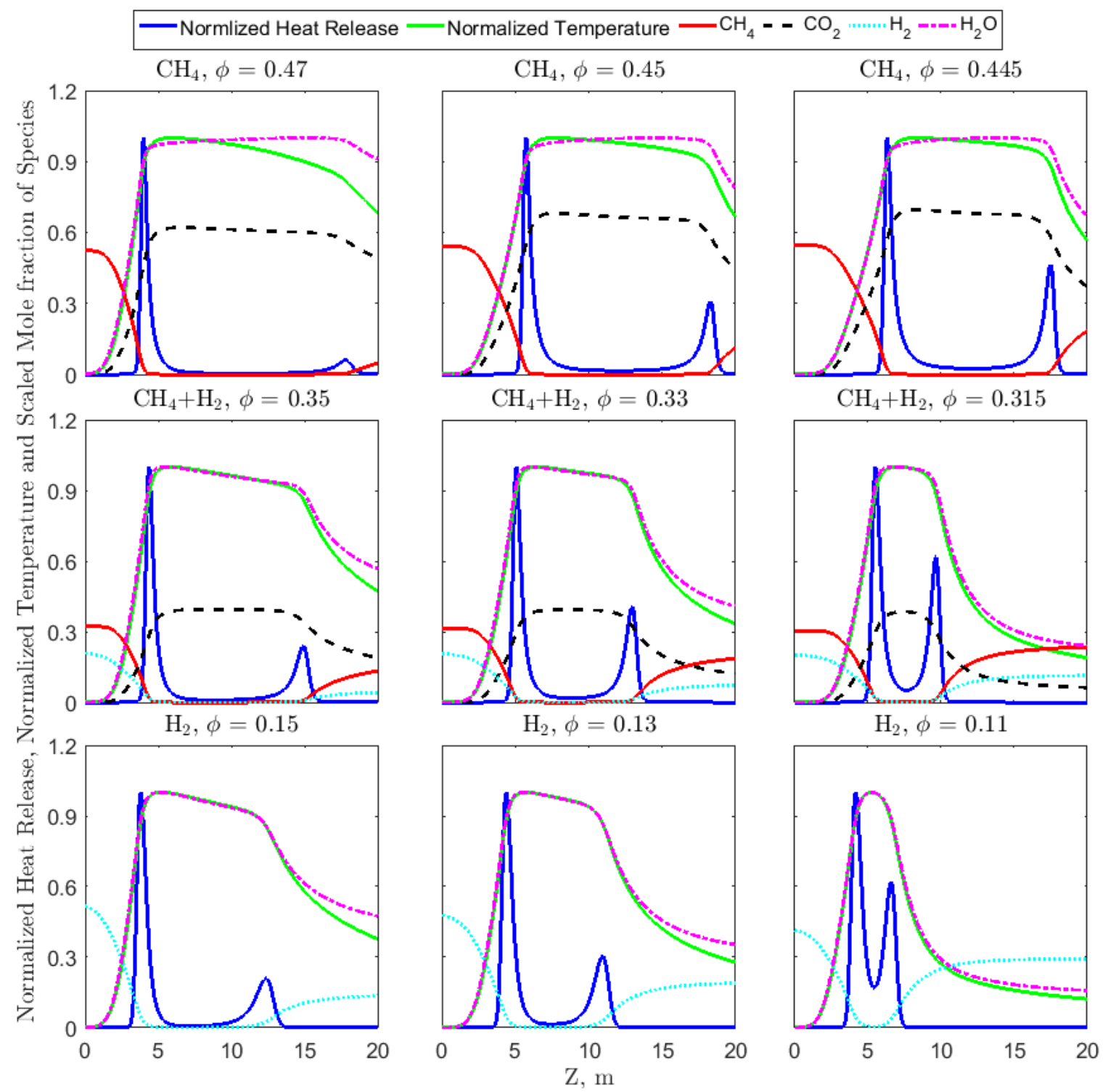

Figure 8: Normalized Heat Release, normalized temperature and scaled mole fraction of species along the centerline of predicted flames for different equivalence ratios with different fuel compositions.

with the increase of temperature, while the diffusive flux of $\mathrm{CH}_{4}$ increases linearly. At the same time, the convective flux of $\mathrm{H}_{2}$ in planar flames decreases much faster in the initial stage of the increase of temperature, while the diffusive flux of $\mathrm{H}_{2}$ rapidly increases, due to the high diffusivity of $\mathrm{H}_{2}$. The sum of the convective and diffusive fluxes of fuel is constant in the preheat zone due to species conservation. Additionally, for the 1D planar flame of the $\mathrm{CH}_{4}-\mathrm{H}_{2}$-air mixture, the diffusive fluxes of $\mathrm{CH}_{4}$ and $\mathrm{H}_{2}$ are comparable in the reaction zone, while the diffusive flux of $\mathrm{H}_{2}$ 

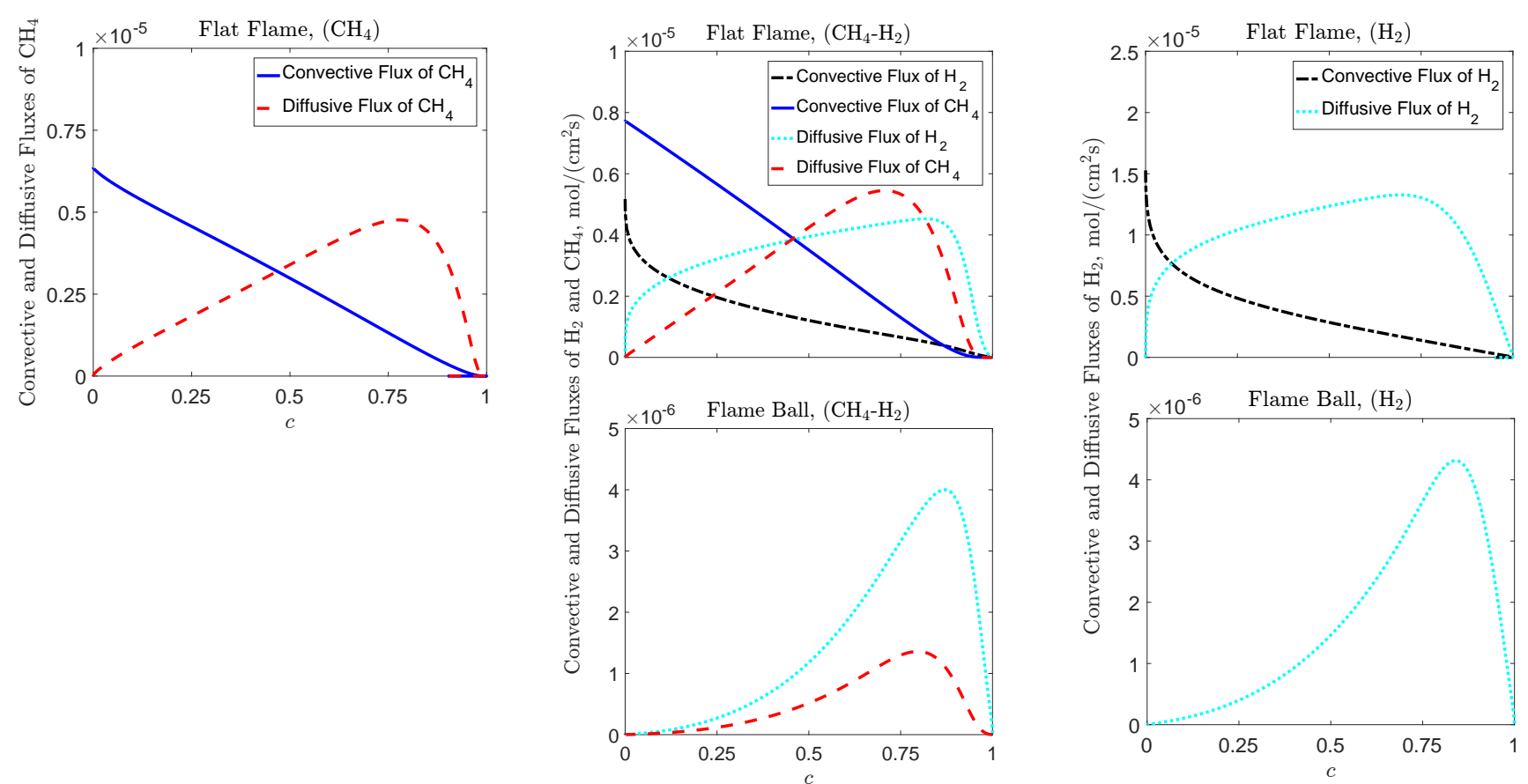

Figure 9: The convective and diffusive fluxes of $\mathrm{CH}_{4}$ and $\mathrm{H}_{2}$ for 1D planar flames and 1D micro-gravity flame balls with different fuel compositions. $\mathrm{CH}_{4}$ (left): $\phi=0.5$ (planar flame); $\mathrm{CH}_{4}-\mathrm{H}_{2}$ (center): $\phi=0.46$ (planar flame) and $\phi$ $=0.275$ (flame ball); $\mathrm{H}_{2}$ (right): $\phi=0.30$ (planar flame) and $\phi=0.08$ (flame ball).

dominates that of $\mathrm{CH}_{4}$ for the 1D micro-gravity flame ball.

The relative role of convection and diffusion in the ball-like flames varies along the flame front. For the flame locations close to the centerline, convection in the preheat zone is important due to the downward (leading edge) and downward/upward (trailing edge) flow. The role of convective transport to/from the flame front in the preheat zone decreases at the flame locations closer to the tube wall because, as shown in Fig. 5, the streamlines are nearly tangential to the flame front at the side flame locations, and these flame sectors are more similar to a flame ball. Since convective transport plays a more important role at the flame locations along the flame centerline, quantities for these regions are plotted and displayed. Figure 10 displays the distributions of the convective and diffusive fluxes of $\mathrm{CH}_{4}$ and $\mathrm{H}_{2}$ for the leading edges of $2 \mathrm{D}$ flames along the centerline of the tube as a function of the normalized temperature with different fuel compositions. It is seen that, for all simulated flames, the convective flux decreases fast with slight increase of temperature and more so with the decrease of equivalence ratio. This indicates that the fuel transport caused by 
convection for the leading edges of 2D lean limit flames plays a less important role, as compared with that in the 1D planar lean limit flame. For the lean limit $\mathrm{CH}_{4}$-air flame, a negative convective flux of $\mathrm{CH}_{4}$ is observed in a part of the preheat zone, indicating that in this region $\mathrm{CH}_{4}$ is transported out of the flame by convection. This is because of the flame negative displacement speed caused by gas recirculation, as shown in Fig. 4(d). At the leading edges of the $2 \mathrm{D} \mathrm{CH}_{4}-\mathrm{H}_{2}$-air flames, the diffusive flux of $\mathrm{H}_{2}$ is larger than that of $\mathrm{CH}_{4}$, which is similar to the distributions of the 1D micro-gravity flame ball (Fig. 9). For $\mathrm{H}_{2}$-air flames, the shape of the diffusive flux of $\mathrm{H}_{2}$ as a function of normalized temperature is more similar to that of the 1D micro-gravity flame ball. This further indicates that convective transport for the leading edges of $2 \mathrm{D}$ lean limit flames is significantly weaker than that for the 1D planar lean limit flame. Additionally, the sum of the convective and diffusive fluxes of the fuel is not constant, indicating that there is an in-flux or out-flux of fuel in the radial direction.

Figure 11 displays the distributions of the convective and diffusive fluxes of $\mathrm{CH}_{4}$ and $\mathrm{H}_{2}$ for the trailing edges of 2D flames at the centerline of the tube as a function of the normalized temperature for different equivalence ratios with different fuel compositions. It is observed that, for all three fuel compositions, the diffusive flux increases with the decrease of equivalence ratio. For most of the simulated cases, the convective flux for the trailing edges is negative, reflecting that fuels are directed out of the trailing edge. Only for the lean limit flames with low Lewis numbers, a small amount of fuel is transported to the trailing edge by convection due to the recirculation zone. The fuel transport at the trailing edges of the 2D flames are dominated by diffusion. Furthermore, the fuel fluxes of the trailing edge are smaller than that of the leading edges. Summarizing these results, the general observed trend is that, for the flames stabilized inside the tube, the convection contribution in the total fuel flux decreases with the decrease of equivalence ratio. For the flames with low Lewis numbers, the diffusive flux profiles resemble the corresponding ones for 1D flame balls as the lean limit is approached, which is an indication of similarity of combustion mechanisms of the studied lean limit flames and 1D micro-gravity flame balls. 


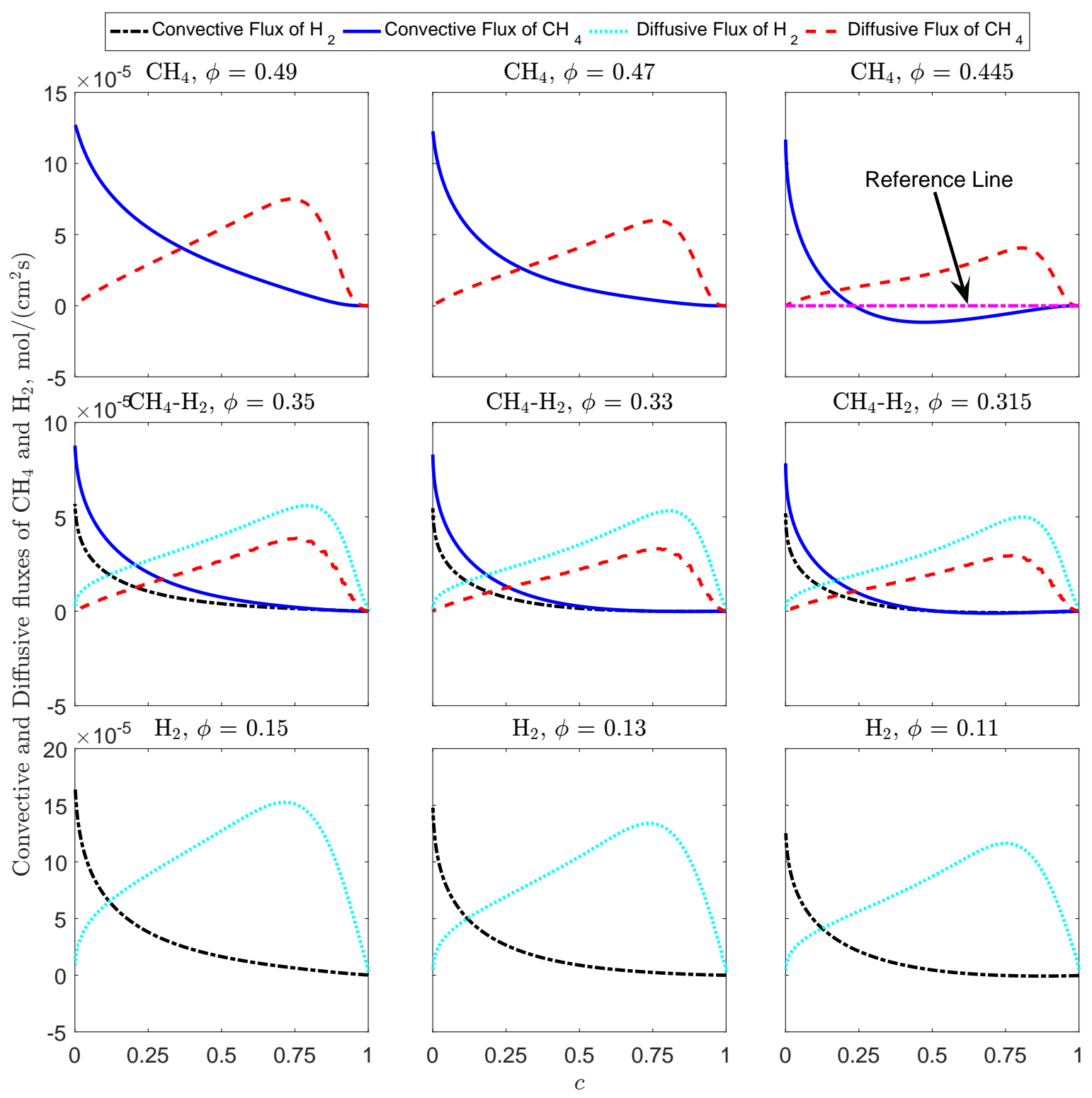

Figure 10: The convective and diffusive fluxes of $\mathrm{CH}_{4}$ and $\mathrm{H}_{2}$ for the leading edges in the centerline of the tube as a function of normalized temperature for different equivalence ratios with different fuel compositions. 


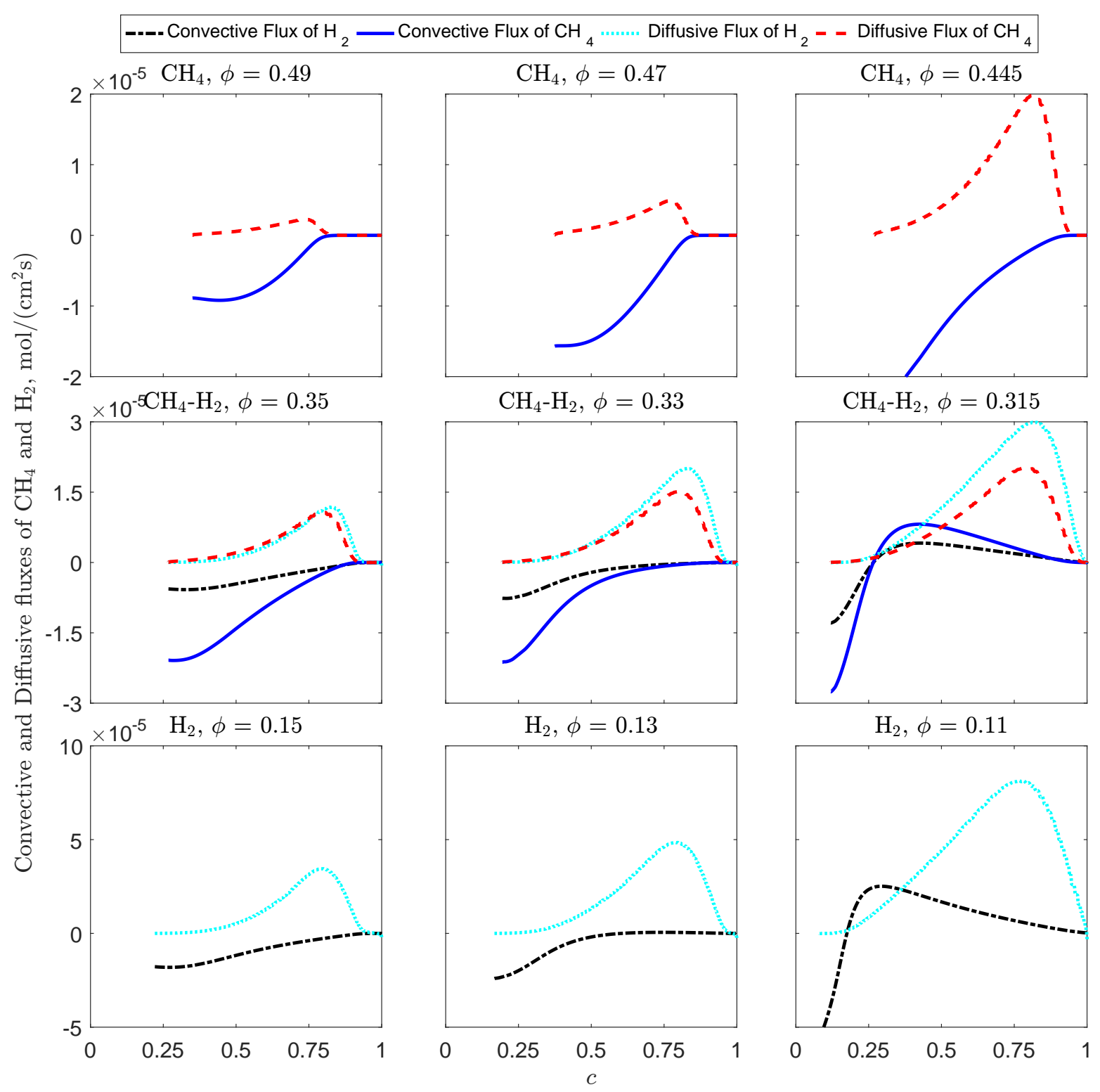

Figure 11: The convective and diffusive fluxes of $\mathrm{CH}_{4}$ and $\mathrm{H}_{2}$ for the trailing edges in the centerline of the tube as a function of normalized temperature for different equivalence ratios with different fuel compositions. The definition of the normalized flame temperature for the trailing edges is the same as that for the leading edges. 


\subsection{Preferential diffusion effect on lean limit flames}

A local equivalence ratio is computed for the simulated cases based a mixture fraction, $\zeta$, which is given by

$$
\phi=\frac{\zeta}{(1-\zeta)} \frac{1-\zeta_{s t}}{\zeta_{s t}}
$$

where $\zeta_{s t}$ denotes the stoichiometric mixture fraction. Bilger's definition of mixture fraction is employed, which is expressed as

$$
\zeta=\frac{\beta-\beta_{o x}}{\beta_{f u}-\beta_{o x}}
$$

where $\beta$ is a coupling function, subscripts $f u$ and $o x$ denote the fuel stream and oxidizer stream, respectively. For a fuel blend of $\mathrm{H}_{2}$ and hydrocarbon $\mathrm{C}_{m} \mathrm{H}_{n}$, with $\mathrm{m}$ and $\mathrm{n}$ referring to the number of atoms of the elements $\mathrm{C}$ and $\mathrm{H}$, respectively, the coupling function $\beta$ based on the element mass fraction is given by

$$
\beta=\frac{Z_{C} / M_{C}}{m(1-\varkappa)}+\frac{Z_{H} / M_{H}}{n(1-\varkappa)+2 \varkappa}-\frac{Z_{O, o x} / M_{O}}{(1-\varkappa)(m+n / 4)+\varkappa / 2}
$$

where $Z_{\alpha}$ is the element mass fraction of $\alpha$ and $M_{\alpha}$ is the molar mass of $\alpha$, with $\alpha=\mathrm{C}, \mathrm{H}$ and $\mathrm{O}$, and $x$ is the molar fraction of $\mathrm{H}_{2}$ in the fuel. The stoichiometric mixture fraction $\left(\zeta_{s t}\right)$ is determined by the following equations

$$
\zeta_{s t}=\frac{\frac{Z_{O, o x} / M_{O}}{(1-\varkappa)(m+n / 4)+\varkappa / 2}}{\frac{Z_{C, f u} / M_{C}}{m(1-\varkappa)}+\frac{Z_{H, f u} / M_{H}}{n(1-\varkappa)+2 \varkappa}+\frac{Z_{O, o x} / M_{O}}{(1-\varkappa)(m+n / 4)+\varkappa / 2}}
$$

For the local equivalence ratio of the $\mathrm{H}_{2}$-air flames, the above equations in this section still hold by removing the terms related to the element of $\mathrm{C}$ with $\varkappa=1$.

Figure 12 shows the distributions of the local equivalence ratio for the lean limit flames with different fuel compositions. Apparent changes in local equivalence ratio for the three flames are observed due to preferential diffusion. The increase in local equivalence ratio is enhanced for the mixtures with smaller Lewis number. Furthermore, a more uniform local equivalence ratio distribution in the high temperature zone is observed for the lean limit flames with $\mathrm{H}_{2}$ content, as compared with the $\mathrm{CH}_{4}$-air flames. Additionally, an area where the local equivalence ratio 


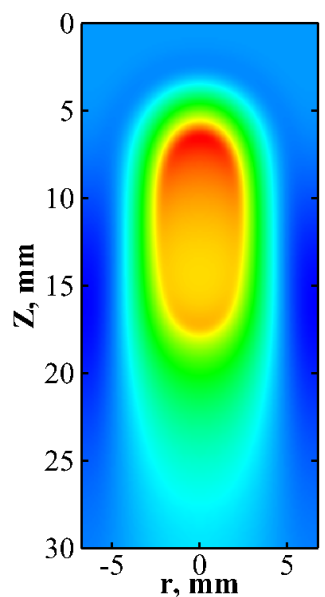

(a) $\phi=0.445$

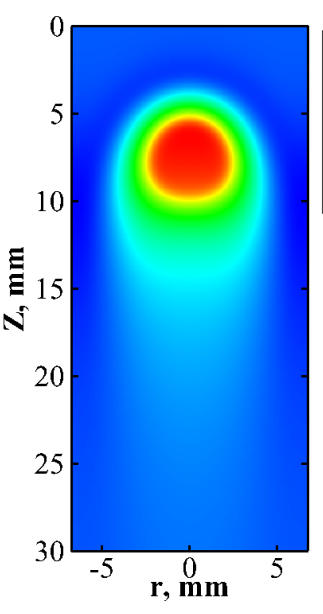

(b) $\phi=0.315$

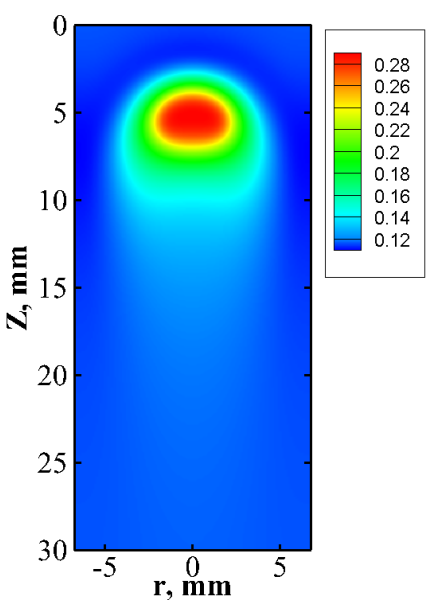

(c) $\phi=0.11$

Figure 12: Distribution of local equivalence ratio for the lean limit flames with different fuel compositions. (a): $\mathrm{CH}_{4}$-air; (b): $\mathrm{CH}_{4}-\mathrm{H}_{2}$-air; (c): $\mathrm{H}_{2}$-air.

diminishes along the upwind side of the flames is observed for the three flames. This is because $\mathrm{H}_{2}$ and $\mathrm{CH}_{4}$ in this area diffuse into the high temperature area more rapidly than $\mathrm{O}_{2}$.

Figure 13 shows the maximum local equivalence ratio for 2D simulated flames as a function of inlet equivalence ratio for mixtures with the three fuel compositions. Also, the maximum local equivalence ratio scaled by the inlet equivalence ratio is plotted in Fig. 13. It is seen that the maximum local equivalence ratio decreases slightly with the decrease of the inlet equivalence ratio for the three fuel compositions. Figure 13 further shows that the scaled maximum local equivalence ratio increases slightly with the decrease of the inlet equivalence ratio for $\mathrm{CH}_{4}$-air and $\mathrm{CH}_{4}-\mathrm{H}_{2}$-air flames, while it increases significantly for $\mathrm{H}_{2}$-air flames. This observation reflects that the influence of preferential diffusion on the local equivalence ratio significantly increases for the mixtures with smaller Lewis number. The maximum local equivalence ratio for the numerical 2D lean limit flames are presented in Table 4 with the inclusion of the maximum local equivalence ratios for the 1D planar lean limit flame and the 1D micro-gravity lean limit flame ball. It shows that the maximum local equivalence ratios for numerical 2D lean limit flames are very close to the ones for 1D micro-gravity lean limit flame balls and 1D planar lean limit flames. 


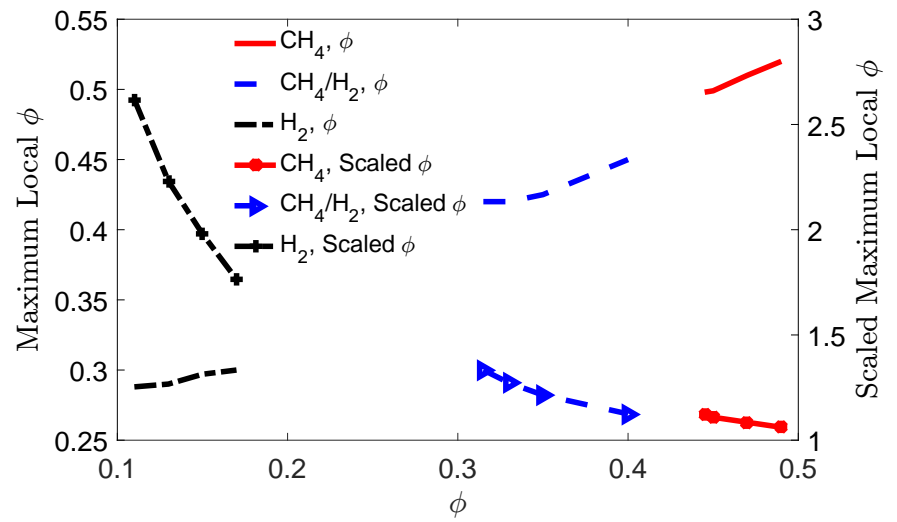

Figure 13: Maximum local equivalence ratio and scaled maximum local equivalence ratio with different fuel compositions as functions of inlet equivalence ratio.

Table 4: Summary of the maximum local equivalence ratio for numerical 2D lean limit flames with different fuel compositions as well as the corresponding maximum local equivalence ratios for 1D planar lean limit flames and 1D lean limit micro-gravity flame balls. The 1D planar flames and 1D micro-gravity flame balls are computed with mixture-averaged transport model and skeletal mechanism for $\mathrm{CH}_{4}$.

\begin{tabular}{ccccc}
\hline Fuel & Le & 2D flame & 1D planar flame & 1D flame ball \\
\hline $\mathrm{CH}_{4}$ & 0.96 & 0.498 & 0.478 & \\
$40 \% \mathrm{H}_{2}+60 \% \mathrm{CH}_{4}$ & 0.7 & 0.433 & 0.436 & 0.441 \\
$\mathrm{H}_{2}$ & 0.296 & 0.288 & 0.298 & 0.301 \\
\hline
\end{tabular}




\section{Summary and Conclusions}

The influence of Lewis number on the lean limit flames inside a tube with an inner diameter of $13.5 \mathrm{~mm}$ is examined by experiment and numerical simulation. Three different fuel compositions with three different fuel Lewis numbers are considered: $\mathrm{CH}_{4}, 40 \% \mathrm{H}_{2}$ and $60 \% \mathrm{CH}_{4}$ fuel composition (specified on a molar basis) and $\mathrm{H}_{2}$. The $\mathrm{CH}^{*}$ chemiluminescence distribution for $\mathrm{CH}_{4}$-air and $\mathrm{CH}_{4}-\mathrm{H}_{2}$-air flames and the $\mathrm{OH}^{*}$ chemiluminescence distribution for $\mathrm{H}_{2}$-air flames are recorded in the experiments. Cell-like flames are observed for $\mathrm{CH}_{4}$-air mixture inside the tube with all tested equivalence ratios. For $\mathrm{CH}_{4}-\mathrm{H}_{2}$-air and $\mathrm{H}_{2}$-air flames, however, ball-like lean limit flames are observed. Numerical simulations are performed with mixture-averaged transport model and skeletal mechanism of $\mathrm{CH}_{4}$. A good qualitative agreement between predicted flames and experimental flames is observed.

The structure of the lean limit flames with three different fuel compositions is analysed by Rayleigh scattering temperature measurement and numerical simulation. A good agreement between measured and simulated temperature profiles is observed for the lean limit flames for all three tested fuel gases. It is further found that the maximum flame temperature for 2D experimental flames, 2D numerical flames, 1D planar flames and 1D flame ball converges to a nearly the same value as the lean limit is approached.

The lean limit flames for $\mathrm{CH}_{4}-\mathrm{H}_{2}$-air and $\mathrm{H}_{2}$-air flames are located inside a recirculation zone, while only the leading edge is located inside the recirculation zone for lean limit $\mathrm{CH}_{4}$-air flame. A flame structure with a negative flame displacement speed is observed for the leading edges of the three predicted lean limit flames. The fuel transport caused by convection at the leading edges of 2D lean limit flames is less significant in 2D lean limit flames as compared with 1D planar flames. For the trailing edges of the three predicted lean limit flames, a diffusion dominated flame structure is observed. To sum up, a more uniform lean limit flame front is observed for lower Lewis number flames. The size of the lean limit flame decreases significantly with decreasing Lewis number. The fuel transport caused by diffusion for the lean limit flames becomes more important with smaller Lewis number, as compared to that caused by convection. The present study provides useful information on the Lewis number effect on the ultra lean combustion behavior and the underlying 
flammability limit mechanisms.

\section{Acknowledgments}

The financial support of the Dutch Technology Foundation (STW), Project 13549, is gratefully acknowledged. The authors thank Prof. Clinton Groth for providing access to the CFFC (Computational Framework for Fluids and Combustion) code.

\section{References}

[1] W. E. Baker, Explosion hazards and evaluation, Elsevier Scientific Pub. Co, 1983.

[2] H. Coward, G. Jones, Limits of flammability of gases and vapors, 1952.

[3] K. Maruta, M. Yoshida, Y. Ju, T. Niioka, Experimental study on methane-air premixed flame extinction at small stretch rates in microgravity, Symp. (Int.) Combust. 26 (1) (1996) 12831289.

[4] L. Qiao, Y. Gu, W. J. A. Dahm, E. S. Oran, G. M. Faeth, Near-limit laminar burning velocities of microgravity premixed hydrogen flames with chemically-passive fire suppressants, Proc. Combust. Inst. 31 (2007) 2701-2709.

[5] L. Qiao, Y. Gan, T. Nishiie, W. J. A. Dahm, E. S. Oran, Extinction of premixed methane/air flames in microgravity by diluents: Effects of radiation and Lewis number, Combust. Flame 157 (8) (2010) 1446-1455.

[6] H. Zhang, R. Fan, S. Wang, X. Tian, K. Xu, S. Wan, F. N. Egolfopoulos, Extinction of lean near-limit methane/air flames at elevated pressures under normal-and reduced-gravity, Proc. Combust. Inst. 33 (1) (2011) 1171-1178.

[7] P. D. Ronney, Near-limit flame structures at low Lewis number, Combust. Flame 82 (1) (1990) 1-14.

[8] Y. Zeldovich, Theory of combustion and detonation of gases, Academy of Sciences (USSR), 1944.

[9] P. D. Ronney, K. N. Whaling, A. Abbud-Madrid, J. L. Gatto, V. L. Pisowicz, Stationary premixed flames in spherical and cylindrical geometries, AIAA J. 32 (3) (1994) 569-577. 
[10] P. D. Ronney, M. S. Wu, H. G. Pearlman, K. J. Weiland, Experimental study of flame ball in space: preliminary results from STS-83, AIAA J. 36 (8) (1998) 1361-1368.

[11] J. Buckmaster, G. Joulin, P. D. Ronney, The structure and stability of nonadiabatic flame balls, Combust. Flame 79 (1990) 381-392.

[12] S. Minaev, L. Kagan, G. Sivashinsky, On self-drifting flame balls, Combust. Theor. Model. 5 (4) (2001) 609-622.

[13] K. Takase, X. Li, H. Nakamura, T. Tezuka, S. Hasegawa, M. Katsuta, M. Kikuchi, K. Maruta, Extinction characteristics of $\mathrm{CH} 4 / \mathrm{O} 2 / \mathrm{Xe}$ radiative counterflow planar premixed flames and their transition to ball-like flames, Combust. Flame 160 (7) (2013) 1235-1241.

[14] R. Fursenko, S. Minaev, H. Nakamura, T. Tezuka, S. Hasegawa, K. Takase, X. Li, M. Katsuta, M. Kikuchi, K. Maruta, Cellular and sporadic flame regimes of low-Lewis-number stretched premixed flames, Proc. Combust. Inst. 34 (1) (2013) 981-988.

[15] R. Fursenko, S. Minaev, H. Nakamura, T. Tezuka, S. Hasegawa, T. Kobayashi, K. Takase, M. Katsuta, M. Kikuchi, K. Maruta, Near-lean limit combustion regimes of low-Lewisnumber stretched premixed flames, Combust. Flame 162 (5) (2015) 1712-1716.

[16] Y. L. Shoshin, L. P. H. de Goey, Experimental study of lean flammability limits of methane/hydrogen/air mixtures in tubes of different diameters, Exp. Therm Fluid Sci. 34 (3) (2010) 373-380.

[17] Y. Shoshin, J. van Oijen, A. Sepman, L. P. H. de Goey, Experimental and computational study of the transition to the flame ball regime at normal gravity, Proc. Combust. Inst. 33 (1) (2011) 1211-1218.

[18] L. Kagan, G. Sivashinsky, Self-fragmentation of nonadiabatic cellular flames, Combust. Flame 108 (1-2) (1997) 220-226.

[19] I. Brailovsky, G. Sivashinsky, On stationary and travelling flame balls, Combust. Flame 110 (4) (1997) 524-529.

[20] F. A. Williams, J. F. Grcar, A hypothetical burning-velocity formula for very lean hydrogenair mixtures, Proc. Combust. Inst. 32 I (2009) 1351-1357.

[21] B. Oostenrijk, Earth gravity flame balls, or are they? Master Thesis, Tech. rep., Eindhoven University of Technology (2012). 
URL http: //purl.tue.nl/923899076843363.pdf

[22] F. E. Hernández-Pérez, B. Oostenrijk, Y. Shoshin, J. A. van Oijen, L. P. H. de Goey, Formation, prediction and analysis of stationary and stable ball-like flames at ultra-lean and normal-gravity conditions, Combust. Flame 162 (4) (2015) 932-943.

[23] J. A. Sutton, J. F. Driscoll, Rayleigh scattering cross sections of combustion species at 266, 355, and $532 \mathrm{~nm}$ for thermometry applications., Opt. lett. 29 (22) (2004) 2620-2622.

[24] X. Gao, C. P. Groth, A parallel solutionadaptive method for three-dimensional turbulent nonpremixed combusting flows, J. Comput. Phys. 229 (9) (2010) 3250-3275.

[25] F. Hernández-Pérez, F. Yuen, C. Groth, Ö. Gülder, LES of a laboratory-scale turbulent premixed Bunsen flame using FSD, PCM-FPI and thickened flame models, Proc. Combust. Inst. 33 (1) (2011) 1365-1371.

[26] California Institute of Technology, CANTERA Release 1.7 (2006).

[27] Reduced kinetic mechanisms and asymptotic approximations for methane/air flames, in: M. D. Smooke (Ed.), Lecture Notes in Physics, Springer-Verlag Heidelberg, 1991, pp. 120.

[28] T. J. Soufiani A., High temperature gas radiative property parameters of statistical narrowband model for $\mathrm{H} 2 \mathrm{O}, \mathrm{CO} 2$ and $\mathrm{CO}$, and correlated-K model for $\mathrm{H} 2 \mathrm{O}$ and $\mathrm{CO} 2$, Int. J. Heat Mass Transfer 40 (4) (1997) 987-991.

[29] Eindhoven University of Technology, A one-dimensional laminar flame code (1994).

[30] T. Okuno, H. Nakamura, T. Tezuka, S. Hasegawa, K. Takase, M. Katsuta, M. Kikuchi, K. Maruta, Study on the combustion limit, near-limit extinction boundary, and flame regimes of low-Lewis-number $\mathrm{CH} 4 / \mathrm{O} 2 / \mathrm{CO} 2$ counterflow flames under microgravity, Combust. Flame 172 (2016) 13-19. 